\title{
Reliability and Validity of Self-Screening Tool for Hearing Loss in Older Adults
}

This article was published in the following Dove Press journal: Clinical Interventions in Aging

\author{
Sunghwa You (iD) ${ }^{1,2}$ \\ Woojae $\operatorname{Han} \mathbb{1}^{1-3}$ \\ Saea Kim iD ${ }^{1,2}$ \\ Sanga Maeng (iD) \\ Young Joon Seo $\mathbb{D D}^{4}$ \\ 'Laboratory of Hearing and Technology, \\ ${ }^{2}$ Division of Speech Pathology and \\ Audiology, ${ }^{3}$ Research Institute of \\ Audiology and Speech Pathology, College \\ of Natural Sciences, Hallym University, \\ Chuncheon, Korea; ${ }^{4}$ Department of \\ Otorhinolaryngology, Yonsei University \\ Wonju College of Medicine, Wonju, \\ Korea
}

Objective: The present study aimed to identify the reliability and validity of a screening tool for the elderly who wish to check their level of hearing loss by themselves.

Design: A total of 170 older adults with different hearing levels participated. The SelfAssessment for Hearing Screening of the Elderly-Revised (SHSE-R) consisted of 20 questions measured on a 5-point scale and developed in terms of characteristics of age-related hearing loss. For reliability, the subjects responded to SHSE-R twice with a three-week interval. They also took various subjective and objective hearing tests and a working memory test and filled out two other questionnaires for validation.

Results: SHSE-R showed a high internal consistency and a high reliability when comparing test-retest scores. Its content validity was as high as $0.88-1$. Convergent validity supported SHSE-R and its subcategories while showing either a positive or negative correlation with pure-tone average, word recognition scores, and otoacoustic emission tests. Construct validity was proved by a moderate negative correlation with the tests of speech in noise, speech with fast speed, and working memory. In criterion validity, a strong positive correlation existed between SHSE-R and the other questionnaires, except for a group with severe hearing loss. The factor analysis showed similar results to the original version of SHSE having three factors, although some items were interchanged.

Conclusion: We confirmed that SHSE-R was well developed with both excellent internal consistency and test-retest reliability and valuable convergent, construct, and criterion validities, consequently making SHSE-R useful for self-checking hearing loss in the elderly. Keywords: hearing screening, self-assessment, questionnaire, age-related hearing loss, older adults

\section{Introduction}

While aging is a global issue, various age-related chronic diseases have been steadily increasing. Among them, presbycusis (or age-related hearing loss) is considered to be the third most common chronic disease of the elderly. ${ }^{1}$ Even so, older adults who suspect hearing loss rarely recognize it by themselves, and thus they sometimes neglect hearing problems and/or underestimate communication difficulty in the early stage due to its slow progress. ${ }^{2}$ Generally, presbycusis is explained as binaural, symmetrical, and high-frequency damage in the cochlear region. ${ }^{3}$ In addition, it is characterized by poor speech understanding in noisy and/ or reverberant environments, ${ }^{4}$ reduced temporal and spectral resolutions, ${ }^{5}$ and negative impact on working memory in terms of cognitive dysfunction, ${ }^{6}$ which induces us to assess these unique features. Because untreated hearing loss can accelerate cognitive decline such as dementia, many health professionals indicate
Correspondence: Woojae Han \#8603 Natural Sciences Bd., I

Hallymdaehak-Gil, Chuncheon 24252,

Republic of Korea

Tel +82-33-248-2216

Fax +82-33-256-3420

Email woojaehan@hallym.ac.kr 
that early diagnosis and rehabilitation of presbycusis should be considered in an aging society. ${ }^{7}$

Although several questionnaires have been used for measuring disability occurring in hearing-impaired people, they failed to focus on the aging problems mentioned above or to diagnose the amount of hearing loss directly with accuracy and convenience, except for the Self-Assessment for Hearing Screening of Elderly (SHSE). ${ }^{8}$ The SHSE offer advantages for simple and fast screening for the degree of presbycusis. It is also easy to calculate and interpret SHSE results. However, the questionnaire's original version needs to be revised. For example, four subcategories in the initial stage of SHSE development were reconstituted with three factors after statistically analyzing the responses of 83 older adults. Some sentences were less comprehensible to read by the elderly themselves and hearing tests used for the validation of SHSE only included subjective types. In addition to these flaws, large numbers of subjects need to be tested and validated statistically for SHSE to become the universal and standardized tool.

The purpose of the present study was to develop a selfreport questionnaire, namely, the Self-Assessment for Hearing Screening of the Elderly - Revised (SHSE-R) and identify its reliability and validity regarding whether it can evaluate the degree of hearing difficulty for older adults who suspect hearing loss. Such a self-assessment tool helps older people increase their likelihood of consulting their hearing professionals as soon as possible as well as to inform them about their hearing condition; ultimately, its results will increase satisfaction with hearing aids and improve the effect of aural rehabilitation through early diagnosis. ${ }^{9}$

\section{Materials and Methods Selection of Items}

Although the SHSE was published through an appropriate process (see Kim et al (2016) for detailed information), ${ }^{8}$ the authors judged that some questions included a few unclear or ambiguous words. Thus, content validity of SHSE was evaluated by eight experts: ${ }^{10}$ two professors in audiology, five clinical audiologists, and one otolaryngologist. After understanding the purpose of the SHSE, they were asked to rate each item using a content validity index (CVI) in terms of its relevance (relation and relevance to the subcategory), clarity (written clearly), simplicity (easy to understand as written), and ambiguity (accuracy of conveying the intent) using a 4-point scale (1: negative, 4 : positive $)^{11-13}$ and also provided comments for better expression. Eleven items rated with scores less than 0.75 were revised. Finally, the original version was modified and designated as SHSE-R.

\section{Participants}

A total of 170 older adults (86 male and 84 female) who visited Wonju Severance Christian Hospital located in Gangwon province participated. Their average age was 72.77 years (SD: 4.92). The participants were included after reporting no history of ear surgery, head trauma, or any other age-related chronic disease and confirming scores higher than 25 on the MiniMental State Examination - Korea (MMSE-K). ${ }^{14}$

To determine the hearing threshold of the individuals, airand bone-conducted testing of pure-tone audiometry was performed. As criteria of the sensorineural hearing loss, only less than $5 \mathrm{~dB}$ air-bone gap was accepted in the testing frequencies. Headphone (TDH 39, Telephonics Co., Farmingdale, USA) and bone transducer headphone (B71, RadioEar, Middelfart, Denmark) were used as the transducer that connected to a clinical audiometer (GSI 61, GransonStadler, Eden Prairie, USA). Based on the levels of hearing loss (i.e., average of pure-tone thresholds at $0.5,1,2$, and 4 $\mathrm{kHz}$, PTA), participants were classified into four groups: 28 with normal hearing and 57, 70, and 15 with mild, moderate, and severe sensorineural hearing loss, respectively. The total sample size was calculated using the G-power program. Specifically, the sample size required for this study was 48 when the effect size was 0.5 , the a-error was 0.05 , the power was 0.8 , and the number of groups was 4 . Because at least 12 subjects were required per group, each group was sufficient to apply for the statistical analysis.

Table 1 explains the demographic and hearing data of the four groups. No significant difference in age existed between the groups $(\mathrm{F}[3169]=2.12, p=0.10)$. However, significant differences in PTA $(\mathrm{F}[3169]=297.21, p=0.00)$ and word recognition score (WRS) among the groups $(\mathrm{F}[3169]=88.98, p=0.00)$ were confirmed. All subjects were native Korean speakers and signed an informed consent form before participating in the experiments. All procedures were approved by the Institutional Review Board of Hallym University (\#HIRB2015-012) and the experiment was conducted in compliance with the Declaration of Helsinki, International Conference of Harmonisation Guidelines for Good Clinical Practice.

\section{Experimental Procedures}

As indicated in Figure 1, all participants were asked to take the SHSE-R and retested again 3 weeks later. Then, they had both behavioral and objective hearing tests. First, the Korean Speech Perception in Noise test ${ }^{15}$ was conducted under $a+3$ 
Table I Demographic Data and Hearing Status of 170 Older Adults as Group Mean and Standard Deviation

\begin{tabular}{|l|l|l|l|l|}
\hline Variable & Normal $(\mathbf{n = 2 8})$ & Mild HL $(\mathbf{n = 5 7 )}$ & Moderate HL $(\mathbf{n}=\mathbf{7 0})$ & Severe HL $(\mathbf{n = 1 5})$ \\
\hline Age, Mean \pm SD & $69.96 \pm 6.05$ & $71.93 \pm 5.71$ & $73.03 \pm 5.23$ & $71.67 \pm 4.23$ \\
\hline $\begin{array}{l}\text { Sex } \\
\text { Female, n (\%) }\end{array}$ & $18(64.3 \%)$ & $36(63.1 \%)$ & $26(37.1 \%)$ & $4(26.7 \%)$ \\
$\quad$ Male, n (\%) & $10(35.7 \%)$ & $21(36.9 \%)$ & $44(62.9 \%)$ & $11(73.3 \%)$ \\
\hline Hearing status & & & & $80.32 \pm 13.02$ \\
PTA, dB, Mean \pm SD & $15.82 \pm 3.61$ & $29.20 \pm 6.72$ & $50.77 \pm 8.07$ & $28.33 \pm 23.97$ \\
WRS, \%, Mean \pm SD & $96.71 \pm 5.56$ & $91.30 \pm 7.49$ & $58.6 \pm 22.32$ & \\
\hline
\end{tabular}

Abbreviations: PTA, pure-tone average; WRS, word recognition scores; SD, standard deviation.

$\mathrm{dB}$ signal-to-noise ratio with babble noise to evaluate the ability of the spectral resolution while presenting 20 sentences of 12 lists pseudo-randomly via a recorded compact disk (CD) and calculating the results as percentages. Second, the Korean Standard Sentence Test ${ }^{16}$ with a slightly fast speed was applied to estimate the ability of the temporal resolution. After developing 30\% time-compressed sentences by using Adobe Audition (Version 5.0; Adobe Systems, Inc., San Jose, CA, USA), the amplitude of each sentence was adjusted by the root mean square. ${ }^{17}$ Ten sentences from eight lists were presented pseudo-randomly via recorded $\mathrm{CD}$ and scored by percentage.

Third, an adaptive digit ordering test consisting of a string of consequent numbers from 0 to 9 in random order was attempted to evaluate the ability of working memory. The maximum length to be repeated by each individual was recorded. Fourth, the Distortion Product Otoacoustic Emission (DPOAE; Madsen Co., Taastrup, Denmark) test was conducted to objectively evaluate a function of hair cells in the cochlea. The thresholds determined were $3 \mathrm{~dB}$ above the noise floor. Finally, participants responded to two questionnaires such as the Korean Hearing Handicap Inventory for the Elderly (KHHIE) ${ }^{18}$ and Korean Evaluation Scale for Hearing Handicap (KESHH) ${ }^{19}$ which are popular for subjectively measuring levels of disability resulting from hearing loss.

\section{Statistical Analysis}

The statistical analysis was conducted with SPSS software (Version 20; IBM Corporation, Armonk, NY, USA) with

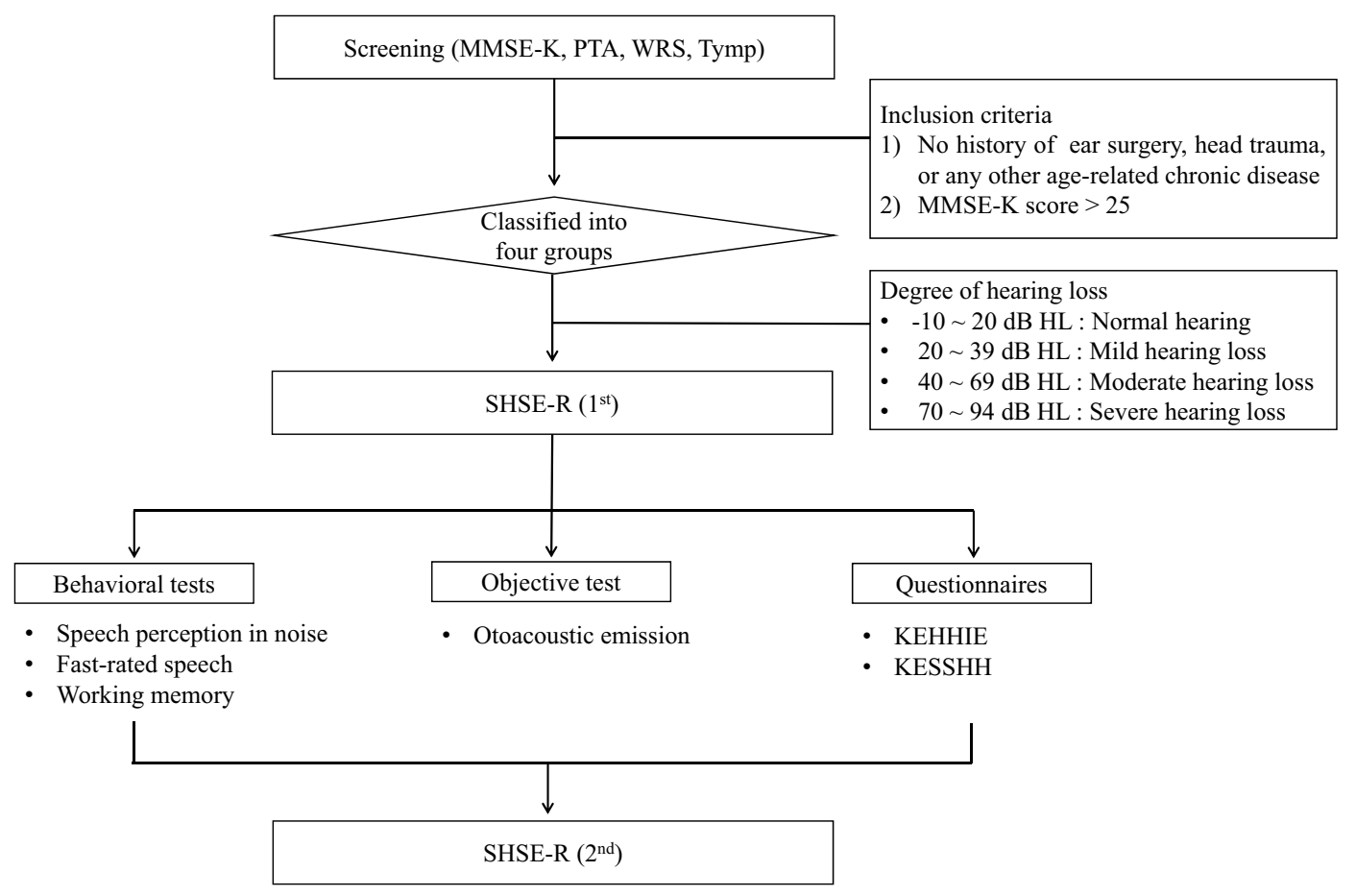

Figure I A flow chart of the experiment procedures. 
$p<0.05$ criteria. To test the significant group difference in age, PTA, WRS, and SHSE-R scores, an analysis of variance (ANOVA) and Bonferroni multiple comparison were applied. Cronbach's $\alpha$ was used to confirm the internal consistency of SHSE. Including a paired $t$-test, Pearson's correlation analysis was used to establish the test-retest reliability, convergent validity (SHSE-R vs PTA, WRS, DPOAE), construct validity (SHSE-R vs speech perception in noise, speech understanding with fast speed, working memory), and criterion validity (SHSE-R vs KHHIE, $\mathrm{KESHH}$ ). In addition, confirmatory factor analysis (CFA) of the SHSE-R was applied with principal axis factoring and varimax.

\section{Results}

\section{Reliability of SHSE-R} Internal Consistency

The total scores of SHSE-R showed high internal consistency of 0.97 of Cronbach's $\alpha$. Three subcategories (eg, general issues, distracting condition, working memory) also showed high values of $0.93,0.94$, and 0.82 , respectively, indicating that they are homogeneous items.

\section{Test-Retest Reliability}

Total scores of the SHSE-R showed significant high reliability $(r=0.96 ; p=0.00)$ with $92 \%$ explanation. Also, its subcategories had high reliability $(r=0.81-0.89, p=0.00)$. Results of paired t-tests supported the reliability in that no significant difference was found between test and retest scores $[\mathrm{t}=1.52, p=0.13]$.

\section{Validity of SHSE-R}

\section{Content Validity}

The SHSE-R items were evaluated by eight professionals (i.e., two gerontologists, two clinical audiologists, two otologists, and two gerontological nurses). The average CVI value of 20 items was 0.88 for relevance, 0.88 for clarity, 1.00 for simplicity, and 0.88 for ambiguity, resulting in the high validity of the SHSE-R. ${ }^{10}$

\section{Convergent Validity}

Figure 2 compares the average scores of four groups. In the first SHSE-R test, the normal hearing and the mild, moderate, and severe hearing loss groups scored 25.93 (SD: 9.23), 36.39 (SD: 14.71), 60.69 (SD: 21.21), and 82.00 (SD: 7.62), respectively. Similarly, the retest scores of the four groups showed 26.22 (SD: 8.60), 36.06 (SD: 15.70), 59.13

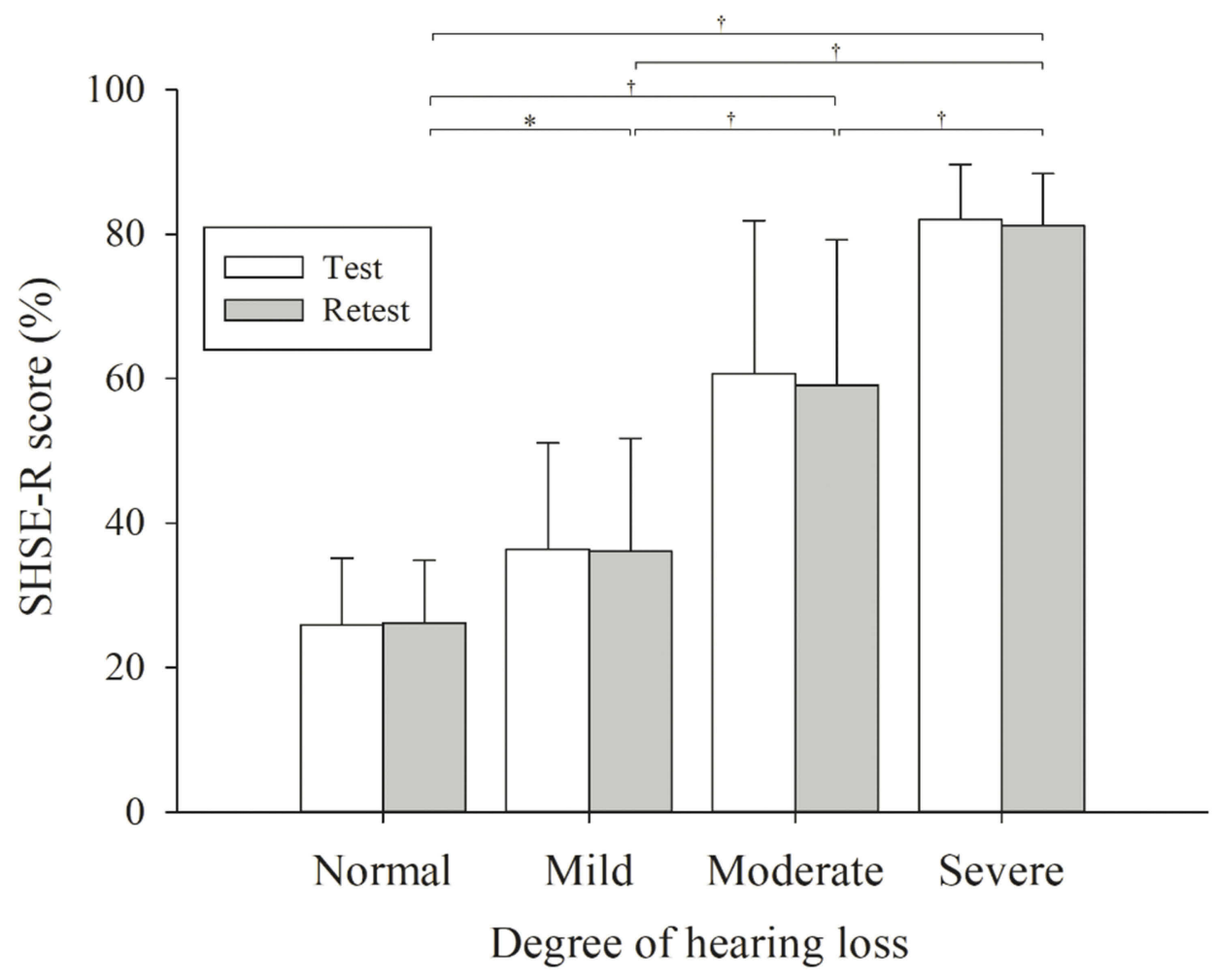

Figure 2 Comparison of test and retest scores for SHSE-R as a function of hearing levels. Notes: $*_{p}<0.05,{ }^{\dagger} p<0.01$. 
Table 2 Correlation of Each Subcategory and Total Score with Three Hearing Tests

\begin{tabular}{|c|c|c|c|c|c|}
\hline & & \multicolumn{4}{|c|}{ Self-Assessment of Hearing Screening of the Elderly - Revised } \\
\hline & & General Issue & Distracting Conditions & Working Memory & Total \\
\hline \multicolumn{2}{|c|}{$\begin{array}{l}\text { Convergent validity } \\
\text { PTA } \\
\text { WRS }\end{array}$} & $\begin{array}{l}0.75^{\dagger} \\
-0.72^{\dagger}\end{array}$ & $\begin{array}{l}0.74^{\dagger} \\
-0.70^{\dagger}\end{array}$ & $\begin{array}{l}0.5 \mathrm{I}^{\dagger} \\
-0.53^{\dagger}\end{array}$ & $\begin{array}{l}0.75^{\dagger} \\
-0.72^{\dagger}\end{array}$ \\
\hline OAEs & $\begin{array}{l}\mathrm{I} \mathrm{kHz} \\
2 \mathrm{kHz} \\
4 \mathrm{kHz} \\
8 \mathrm{kHz}\end{array}$ & $\begin{array}{l}-0.49^{\dagger} \\
-0.38^{\dagger} \\
-0.37^{\dagger} \\
-0.42^{\dagger}\end{array}$ & $\begin{array}{l}-0.52^{\dagger} \\
-0.41^{\dagger} \\
-0.40^{\dagger} \\
-0.44^{\dagger}\end{array}$ & $\begin{array}{l}-0.40^{\dagger} \\
-0.28^{\dagger} \\
-0.34^{\dagger} \\
-0.34^{\dagger}\end{array}$ & $\begin{array}{l}-0.52^{\dagger} \\
-0.40^{\dagger} \\
-0.40^{\dagger} \\
-0.43^{\dagger}\end{array}$ \\
\hline $\begin{array}{l}\text { Constr } \\
\text { Speech } \\
\text { Fast rat } \\
\text { Workin }\end{array}$ & $\begin{array}{l}\text { alidity } \\
\text { se } \\
\text { peech } \\
\text { hory }\end{array}$ & $\begin{array}{l}-0.52^{\dagger} \\
-0.54^{\dagger} \\
-0.34^{\dagger}\end{array}$ & $\begin{array}{l}-0.48^{\dagger} \\
-0.53^{\dagger} \\
-0.34^{\dagger}\end{array}$ & $\begin{array}{l}-0.35^{\dagger} \\
-0.41^{\dagger} \\
-0.27^{\dagger}\end{array}$ & $\begin{array}{l}-0.50^{\dagger} \\
-0.53^{\dagger} \\
-0.34^{\dagger}\end{array}$ \\
\hline \multicolumn{6}{|c|}{ Criterion validity of each group (normal/mild/moderate/severe) } \\
\hline \multicolumn{2}{|c|}{$\begin{array}{l}\text { KHHIE } \\
\text { KESHH }\end{array}$} & $\begin{array}{l}0.74^{\dagger} / 0.71^{\dagger} / 0.61^{\dagger} / 0.30 \\
0.52^{\dagger} / 0.51^{\dagger} / 0.69^{\dagger} /-0.08\end{array}$ & $\begin{array}{l}0.78^{\dagger} / 0.75^{\dagger} / 0.73^{\dagger} /-0.01 \\
0.65^{\dagger} / 0.57^{\dagger} / 0.83^{\dagger} / 0.10\end{array}$ & $\begin{array}{l}0.65^{\dagger} / 0.60^{\dagger} / 0.57^{\dagger} / 0.7 I^{*} \\
0.60^{\dagger} / 0.39^{\dagger} / 0.61^{\dagger} / 0.56\end{array}$ & $\begin{array}{l}0.79^{\dagger} / 0.76^{\dagger} / 0.7 I^{\dagger} / 0.40 \\
0.64^{\dagger} / 0.56^{\dagger} / 0.8 I^{\dagger} / 0.16\end{array}$ \\
\hline
\end{tabular}

Notes: $* p<0.05,{ }^{\dagger} p<0.01$.

Abbreviations: PTA, pure-tone average; WRS, word recognition scores; OAEs, otoacoustic emissions; KHHIE, Korean Hearing Handicap Inventory for the Elderly; KESHH, Korean Evaluation Scale for Hearing Handicap.

(SD: 20.09), and 81.17 (SD: 7.17), respectively. As the hearing loss increases, the SHSE-R scores are significantly increased. The SHSE-R total scores were significantly differentiated in four groups for the test $(\mathrm{F}[3166]=53.69, p=0.00)$ and retest $(\mathrm{F}[3166]=52.07, p=0.00)$. When applied for Bonferroni multiple comparisons, the difference in SHSE-R total scores between the groups was confirmed statistically $(p<0.05)$.

The convergent (or discriminant) validity was checked by the significant correlations between the SHSE-R scores and three hearing tests of PTA, WRS, and DPOAE. Table 2 represents their correlation values. In detail, strong positive and negative correlations existed between total scores and PTA $(r=0.75)$ and WRS $(r=-0.72)$, although either a moderate positive or negative correlation was confirmed with the category of working memory. Four testing frequencies of OAEs resulted in a moderate negative correlation with subcategory and total scores of SHSE-R $(r=-0.40 \sim-0.52)$. In sum, the objective test is a relatively weaker correlation with the SHSE-R score than behavioral tests, but the convergent validity supports that SHSE-R scores are reasonable to measure the degree of hearing loss.

\section{Construct Validity}

The total and subcategory scores of SHSE-R were compared with results of speech perception in noise, fast-rate of speech, and working memory. Table 2 displays a moderate negative correlation with the speech perception in noise $(r=-0.35$ to $-0.52)$ and fast rate of speech $(r=-0.41$ to -0.54$)$. That is, the higher SHSE-R scores indicate more difficulty in speech understanding under noise and poor recognition in fast rate of speech. The maximum length of the working memory showed a relatively weak correlation with SHSE-R scores $(r=-0.27$ to -0.34$)$.

\section{Criterion Validity}

The criterion (or concurrent) validity was confirmed through significant correlations between the SHSE-R scores and two hearing handicap questionnaires such as KHHIE and KESHH. As indicated in Table 2, either subcategory or total score of SHSE-R significantly showed a strong positive correlation with both KHHIE and KESHH in normal hearing ( $r=0.79$ and 0.64$)$, mild hearing loss $(r=0.76$ to $0.56)$, and moderate hearing loss $(r=0.714$ to 0.805$)$. However, the group with severe hearing loss showed no significant relation $(r=-0.40$ and 0.16$)$.

\section{Exploratory Factor Analysis}

The Kaiser-Meyer-Olkin test measured the sampling adequacy ratio of SHSE-R and found it was 0.95, explaining that SHSE-R was quite appropriate for exploring the factor structure. In addition, Bartlett's test of sphericity showed that the correlation matrix was significantly different from the identity matrix and, thus, was factorable for 
exploratory factor analysis (EFA), $\chi^{2}(d F=190)=$ 3349.72, $p=0.00$. When using principal axis factoring and varimax, the EFA resulted in three factors. To determine number of factors, more than 1.0 eigenvalues were extracted. Then, only factors explaining at least $5 \%$ of the variance and only items with factor loading values of 0.05 or greater on a single factor were considered. As a result, three factors were extracted in the SHSE-R. The eigenvalue was 12.17 (factor 1), 1.78 (factor 2), and 1.25 (factor 3) and a total of the variances was 75.04. Table 3 displays the results of factor analysis.

The SHSE-R consisted of 12 questions for general issues, 4 questions for the distracting conditions, and 4 questions for the working memory. Six items of the general issue were moved from the distracting condition of the original version, resulting in becoming a specific and strong category for problems of presbycusis. The subcategory of the distracting condition and working memory in the revised version was interchanged by only one item from other categories, while leaving the delicate items. The formal version of the SHSE-R that elderly people can use by themselves is included in the Appendix.

\section{Discussion}

The purpose of the present study was to develop and verify the SHSE-R questionnaire that was designed to assess the degree of hearing loss and its difficulty in the elderly. The developed SHSE-R had high internal consistency with three subcategories to measure homogeneous content and high reliability of test-retest scores while being

Table 3 Components Loadings from the EFA for the 20 Items of the SHSE-R

\begin{tabular}{|c|c|c|c|c|c|}
\hline \multirow[t]{2}{*}{ Component } & \multirow{2}{*}{$\begin{array}{l}\text { Item } \\
\text { No. }\end{array}$} & \multirow[t]{2}{*}{ Question } & \multicolumn{3}{|c|}{ Factor } \\
\hline & & & $\mathbf{I}$ & 2 & 3 \\
\hline \multicolumn{3}{|c|}{ Factor I. General issues } & & & \\
\hline $\mathrm{D}$ & 10 & $\begin{array}{l}\text { Do you have difficulty understanding speech in a reverberating location (e.g., cathedral, indoor } \\
\text { swimming pool)? }\end{array}$ & 0.87 & & \\
\hline $\mathrm{D}$ & 9 & Do you find it difficult to talk to people in noisy places (e.g., restaurant, subway)? & 0.86 & & \\
\hline G & I & Do you have difficulty understanding when someone talks too quietly? & 0.83 & & \\
\hline G & II & Do you have difficulty understanding the conversation when several people talk at the same time? & 0.82 & & \\
\hline G & 3 & Do you have difficulty understanding mumbled or unclear voices? & 0.82 & & \\
\hline G & 6 & Do you wish to increase the TV's volume when watching it with family because the sound is not clear? & 0.81 & & \\
\hline $\mathrm{D}$ & 8 & Do you have difficulty hearing the announcements on public transport (e.g., bus, subway)? & 0.80 & & \\
\hline G & 5 & Have you ever misunderstood or responded inappropriately to what someone said? & 0.79 & & \\
\hline $\mathrm{D}$ & 2 & Do you have difficulty hearing sounds such as birds and crickets singing or water flowing? & 0.78 & & \\
\hline $\mathrm{D}$ & 13 & Do you find it difficult to understand what others are saying on the phone? & 0.74 & & \\
\hline G & 4 & $\begin{array}{l}\text { Do you find it difficult to understand an unfamiliar voice (e.g., stranger) compared to a familiar } \\
\text { voice (e.g., friend, family)? }\end{array}$ & 0.70 & & \\
\hline $\mathrm{D}$ & 12 & $\begin{array}{l}\text { Have you missed hearing a doorbell when a guest has visited your house (if there is no doorbell, } \\
\text { a knock or a voice calling to you)? }\end{array}$ & 0.69 & & \\
\hline \multicolumn{3}{|c|}{ Factor 2. Distracting condition } & & & \\
\hline $\mathrm{D}$ & 15 & Have you ever felt that the TV or radio sound is too fast? & & 0.83 & \\
\hline D & 16 & $\begin{array}{l}\text { Have you ever asked a communication partner to speak slowly because you feel his or her speech } \\
\text { is too fast? }\end{array}$ & & 0.79 & \\
\hline $\mathrm{D}$ & 14 & $\begin{array}{l}\text { Do you have difficulty communicating in a dark environment where the face is not clearly visible } \\
\text { (expression and mouth shape)? }\end{array}$ & & 0.66 & \\
\hline G & 7 & Have you ever heard that your voice is too loud when you speak? & & 0.60 & \\
\hline \multicolumn{3}{|c|}{ Factor 3. Working memory } & & & \\
\hline W & 20 & Have you ever asked someone to repeat what you just said because you did not remember? & & & 0.78 \\
\hline W & 19 & $\begin{array}{l}\text { Have you ever wandered the store aisles because you could not remember after hearing the } \\
\text { location of the item you were looking for? }\end{array}$ & & & 0.71 \\
\hline W & 17 & Have you ever found it difficult to remember the first half while listening to a rather long story? & & & 0.61 \\
\hline $\mathrm{D}$ & 18 & Have you ever asked someone to repeat what was said during a conversation? & & & 0.56 \\
\hline
\end{tabular}


significantly differentiated in the four groups for both test and retest results. By revising the questionnaire, the total scores were decreased more than SHSE and more significantly differentiated among the group. Specifically, the SHSE total score for each group decreased under test conditions, 18.31, 18.88, 5.92, and 3.85, in the normal hearing and mild, moderate, and moderate-to-severe hearing loss groups, respectively. In other words, subjects with hearing closer to normal scored lower, while those with moderate or severe hearing loss scored higher. These results suggest that the SHSE-R more distinctly differentiated the degree of hearing loss.

Content, convergent, construct, and criterion validations of the SHSE-R were performed by statistical evidence. When considering that the proportion of all items can exceed 0.75 , the SHSE-R had high content validity. Unfortunately, although it showed a relatively weak correlation between objective test and SHSE-R score, the convergent validity showed that the SHSE-R scores can reflect the degree of hearing loss. In addition, the construct validity for moderate correlation with subcategories and the hearing tests indicates that higher SHSE-R scores mean greater difficulty in perceiving speech under a noisy environment and poor ability in fast rate of speech. Regardless, the category of the working memory and the working memory test did not show a strong enough relation. We assume any limitation of digit tests applied in the present study, although we changed the general digit test measured in the original version ${ }^{8}$ into the adaptive digit ordering test in the revised version ${ }^{6}$ due to no significant correlation between them. The criterion validity showed that the SHSE-R subcategory scores and total score with KHHIE and KESHH have a significant and high correlation in normal hearing to moderate hearing loss, but the severe hearing loss group showed a lower correlation that was not significant. These results may be due to the relatively small number of subjects in the severe group.

For the results of EFA, based on eigenvalue and variance, three factors were extracted in the SHSE-R: general issues, distracting condition, and working memory. These three factors are the same as in SHSE, but the composition items of each factors are shifted (see the first row of Table 3). For instance, the SHSE's subcategories consisted of 10, 7, and 3 items in general issues, distracting condition, and working memory, respectively. However, SHSE-R consisted 12, 4, and 4 items in the same subcategories. In more detail, questions 2, 8-10,12, and 13 represented the distracting condition in SHSE, but these questions were shifted to general issues in SHSE-R. Also, question 7, general issues in SHSE, shifted the distracting condition in SHSE-R, and question 18 in the distracting condition in SHSE shifted working memory in SHSE-R. The movement in factors of these items may be caused by the following reasons; general issues and distracting conditions are classified according to distinct factors that are statistically distinguished, but the two factors cannot be clearly distinguished. That is, the movement between the two factors is considered a feature of the general presbycusis that can coexist with two subcategories. ${ }^{4,5}$

Although most validation evaluations of the SHSE-R showed a strong correlation with various subject and object tests, four groups failed to include the same number of subjects as the limitation of the study. In the real world, considering the relatively small number of normal or severe hearing loss patients visited in clinic or hospital, the current results are realistic but should be considered in future studies. If constructing a Web or application device, we expect that the SHSE-R will be more convenient and highly accessible for the elderly so that many older adults can use it. ${ }^{9}$ Also, improved awareness of presbycusis, which is often misunderstood and underestimated, can increase accessibility in terms of diagnosis. Therefore, the SHSE-R needs to be translated and standardized into the languages of many countries of the world to become an international hearing screening tool.

\section{Acknowledgment}

This work was supported by Hallym University Research Fund (HRF-201810-009).

\section{Disclosure}

The authors report no conflicts of interest in this work.

\section{References}

1. Li-Korotky HS. Age-related hearing loss: quality of care for quality of life. Gerontologist. 2012;52(2):265-271.

2. Davis A. Population study of the ability to benefit from amplification and the provision of a hearing aid in 55-74-year-old first-time hearing aid users. Int $J$ Audiol. 2003;42(sup2):39-52. doi:10.3109/149920 20309074643

3. Liu XZ, Yan D. Ageing and hearing loss. J Pathol. 2007;211 (2):188-197. doi:10.1002/(ISSN)1096-9896

4. Helfer KS, Wilber LA. Hearing loss, aging, and speech perception in reverberation and noise. J Speech Lang Hearing Res. 1990;33 (1):149-155. doi:10.1044/jshr.3301.149

5. Pichora-Fuller MK, Singh G. Effects of age on auditory and cognitive processing: implications for hearing aid fitting and audiologic rehabilitation. Trends Amplif. 2006;10(1):29-59. doi:10.1177/1084713 80601000103

6. Arehart KH, Souza P, Baca R, Kates JM. Working memory, age and hearing loss: susceptibility to hearing aid distortion. Ear Hear. 2013;34(3):251. doi:10.1097/AUD.0b013e318271aa5e 
7. You S, Han W. Approaching knowledge, attitudes, and practices model for elderly with dementia who are suspected to have hearing impairment in Korea. J Audiol Otol. 2019. E-pub ahead of print.

8. Kim G, Na W, Kim G, Han W, Kim J. The development and standardization of self-assessment for hearing screening of the elderly. Clin Interv Aging. 2016;11:787.

9. Yu J, Jeon H, Song C, Han W. Speech perception enhancement in elderly hearing aid users using an auditory training program for mobile devices. Geriatr Gerontol Int. 2017;17(1):61-68. doi:10.1111/ggi.12678

10. Lynn MR. Determination and quantification of content validity. Nurs Res. 1986;35:382-386. doi:10.1097/00006199-198611000-00017

11. DeVellis RF. Scale Development: Theory and Applications (Applied Social Research Methods Series, Vol. 26). Newbury Park: Sage; 1991.

12. Polit D, Hungler B. Nursing Research: Principles and Methods. 6th ed. Philadelphia: Lippincott; 1999.

13. Smith SL, Pichora-Fuller KM, Watts KL, et al. Development of the listening self-efficacy questionnaire (LSEQ). Int $J$ Audiol. 2011;50:417-425. doi:10.3109/14992027.2011.553205
14. Kang YW. A normative study of the Korean-Mini Mental State Examination (K-MMSE) in the elderly. Korean J Psychol. 2006;25 (2):1-12.

15. Kim JS, Bae SY, Lee JH. Development of a test of Korean speech intelligibility in noise (KSPIN) using sentence materials with controlled word predictability. Korean J Speech Sci. 2000;7(2):37-50.

16. Jang HS, Lee JH, Lim DW, Lee KW, Jeon AR, Jung EJ. Development of Korean standard sentence lists for sentence recognition tests. Audiology. 2008;4:161-177.

17. Nastase AS (2015). How to derive the RMS value of pulse and square waveforms. Available from: MasteringElectronicsDesign. com. Accessed 21 January, 2015.

18. Ku HL, Kim JS. Test-retest reliability of the Korean Hearing Handicap Inventory for the Elderly (KHHIE). Commun Sci Disord. 2000;5(1):1-22.

19. HL K, JS K. The study for standardization of the Korean Evaluation Scale for Hearing Handicap. Audiology Speech Res. 2010;6:128-136. doi:10.21848/audiol.2010.6.2.128
Clinical Interventions in Aging

\section{Publish your work in this journal}

Clinical Interventions in Aging is an international, peer-reviewed journal focusing on evidence-based reports on the value or lack thereof of treatments intended to prevent or delay the onset of maladaptive correlates of aging in human beings. This journal is indexed on PubMed Central, MedLine, CAS, Scopus and the Elsevier

\section{Dovepress}

Bibliographic databases. The manuscript management system is completely online and includes a very quick and fair peer-review system, which is all easy to use. Visit http://www.dovepress.com/ testimonials.php to read real quotes from published authors. 